\title{
Ana Berstein: a crítica cúmplice
}

Vilma Arêas*

A Crítica Cúmplice - Décio de Almeida Prado e a Formação do Teatro Moderno Brasileiro, Ana Berstein, Instituto Moreira Salles, 2005.

Qualquer comentário sobre A Crítica Cúmplice - Décio de Almeida Prado e a Formação do Teatro Brasileiro Moderno de Ana Berstein deve estabelecer o ponto de partida do ensaio para avaliar devidamente seu sentido e alcance. Trata-se de uma dissertação de mestrado em História Social da Cultura, editada com esmero pelo Instituto Moreira Sales, e elaborada de 1993 a 1995 sob a orientação de Flora Süssekind, no programa de pós-graduação da PUC/RJ. A autora obedece, assim, às novas orientações e prazos vigentes no Brasil para a produção acadêmica. Digo isso, não para diminuir o ensaio. Ao contrário, para ressaltá-lo, pois raras pessoas conseguem nesse tempo record elaborar algo de útil e importante, qualidades do livro que temos nas mãos.

É verdade que a autora tem um percurso diferenciado e uma vinculação incomum com o universo teatral, o que a distingue dos pesquisadores acadêmicos de praxe. Foi crítica de teatro no Jornal do Brasil entre 1992 e 1993 e no Jornal de Artes Cênicas em 1994, desenvolvendo também um trabalho regular de atriz durante os anos 80. Uma das peças, Baden Baden e a Didática de Estar de Acordo, de Brecht, deu-se sob a direção de José Celso Martinez Corrêa. Uma vez terminada a dissertação, Ana foi curadora de festivais internacionais de teatro no Rio de Janeiro, diretora da Divisão de Artes Cênicas da RioArte e ainda organizou um ciclo de debates sobre a crítica teatral no teatro Glória.

Essa carreira diversificada, centrada embora no teatro, não deixa de espelhar de algum modo o percurso de Décio -ator e diretor amador, escritor, crítico militante, acadêmico e pesquisador- com as diferenças impostas a Bernstein pela transformação do trabalho intelectual, questão que é tematizada no livro. 0 tempo estreitou o espaço e as possibilidades de interferência cultural da arte e sua crítica, enfraquecendo, no caso do teatro, o contato entre trabalho inte-

* professora no Instituto de Estudos da Linguagem da UNICAMP e autora de, entre outros, Trouxa Frouxa (2000) e Clarice Lispector (2005), ambos pela Companhia das Letras. 
lectual sistemático e prática cênica, conforme sublinha Flora Süssekind em seu prefácio ao ensaio. Um dos exemplos citados por Ana, de interferência e harmonia entre trabalho teórico e prática teatral, foi a sugestão de Décio feita a dois alunos, um deles o diretor José Renato, para que adotassem o formato arena (daí o nome do nosso teatro) para barateamento das montagens, à inspiração do Theatre-in-the-Round, desenvolvida por Margo Jones no Dallas Civic Theatre, experiência pioneira nos Estados Unidos (p.147).

Apesar da intensa atividade antes e depois da pesquisa, Bernstein fez um levantamento minucioso do percurso intelectual e da obra de Almeida Prado, determinando os pontos de apoio das escolhas estéticas do autor, os princípios que as regulam e suas transformações no correr do tempo. Além disso, como o tema do ensaio é não apenas o crítico, mas a crítica por ele elaborada, Bernstein contextualiza o encontro feliz, mas não fortuito, da renovação de nosso teatro (preparada pela atuação dos grupos amadores na década de 1930) com o surgimento da verdadeira crítica teatral, consequência da elevação da temperatura intelectual pela criação da Universidade de São Paulo. Esta, por sua vez, tornou possíveis as condições para a existência da revista Clima da década seguinte, fundada por seus antigos alunos, que provaram ser mais tarde "algumas das maiores e mais influentes vocações críticas da cultura e das artes brasileiras" ${ }^{1}$ no século XX.

Em entrevista de $1997^{2}$ Décio reconhece que o grupo a que pertenceu dedicou-se "às raízes do País: Antonio Candido na literatura; Paulo Emílio no cinema; Gilda de Mello e Souza, na pintura do século XIX”. Acrescentamos: ele, no teatro. ${ }^{3}$ Muito havia que fazer no meio acanhado de São Paulo na época, com avenidas e bairros residenciais de que os paulistas se orgulhavam, mas também com "a pobreza, o atraso, a caipirice, as boiadas atropelando os bondes"4 etc, que valeu o poema de Oswald de Andrade analisado por Roberto Schwarz ${ }^{5}$, lembrado pela ensaísta.

1 Cf. Pontes, Heloisa. Destinos mistos -os criticos do Grupo Clima em São Paulo, 1940-1968, S. Paulo, Companhia das Letras, 1998, a respeito dos processos sócio-culturais desses anos.

20 Estado de S. Paulo, 9/ago/1997.

3 Cf. Arantes, Paulo. "Décio de Almeida Prado e o papel do teatro no sistema da cultura brasileira", em Revista Vozes nº 6, nov/dez 1995.

4 Prado, Décio de Almeida. "Saudades de Lévi-Strauss", Jornal de Resenhas, Discurso Editorial/USP/Folha de S. Paulo, 12/abr/1996.

5 Schwarz, Roberto, "A carroça, o bonde e o poeta modernista", Que horas são?, São Paulo, Companhia das Letras, 1987. 
Quanto à literatura, nosso autor afirma que os modernistas eram muito pouco lidos."Mário de Andrade fez uma tiragem de 800 exemplares de Macunaima e, ainda assim, guardava um monte deles em casa. Quanto ao teatro a coisa é ainda mais complexa. Conta com muita gente em sua preparação e não se pode fazê-lo sem pensar em se ter um mínimo de público" . Em consequência era quase inexistente além do repertório "para rir" (por isso Décio chegou a pensar em ser crítico de cinema). Uma guerra mundial rebatia numa ditadura caseira, exercitando sua censura (Procópio queixandose de que não podia falar a palavra "amante", Cacilda Becker proibida de falar a palavra "gatuno" no grupo amador liderado por Décio ${ }^{7}$ ).

A Critica Cúmplice sublinha o caráter inaugural do trabalho de Almeida Prado nesse contexto, pois antes dele a crítica não passava de mero registro jornalístico e social. Ele próprio confessa ${ }^{8}$ não se lembrar do nome do suposto crítico que o antecedeu em $O$ Estado de $S$. Paulo, sabendo apenas que ele cobria principalmente turismo ${ }^{9}$. Todo esse cenário passou a se modificar a partir da revista Clima - onde o futuro autor de João Caetano colaborou de 1941 a 1944 e em O Estado de S. Paulo, de 1946 a 1968, ao lado de Sábato Magaldi. 0 mesmo cenário anterior explica a "cumplicidade" do crítico em relação a seu objeto de estudo, postura intelectual partilhada por todo o grupo de Clima. Equipara-se à "paixão do concreto" referida por Gilda de Mello e Souza, à defesa da crítica educativa por Lourival Gomes Machado, por conta do abismo entre "as elites e a massa" no Brasil, e à crítica interessada de Antonio Candido, conforme lemos na Introdução à Formação da Literatura Brasileira. Nessa linha Décio se esforçou para que nosso teatro se desenvolvesse e ampliasse o repertório, tarefa dos Comediantes, no Rio, que marcaram o início do bom teatro contemporâneo entre nós ${ }^{10}$, e dos grupos amadores em São Paulo; o encenador, que chegou com Ziembinski, completou a modernização de nosso palco. 0 empenho dessa crítica, entretanto, nada tinha de ufanista, ou de mero "entusiasmo

6 O Estado de S. Paulo, 9/ago/1997.

7 Revista Bravo, março de 2000.

8 Idem.

90 turismo significava as primeiras excursões de automóvel (de São Paulo a Santos ou, "maior aventura”, de São Paulo ao Rio), "uma coisa que depois desapareceu". (Revista Bravo. cit.)

10 Cf. Magaldi, Sábato. "Panorama Contemporâneo", Panorama do Teatro Brasileiro. Rio de Janeiro, MEC/DAC /FUNARTE/SERVIÇO NACIONAL DE TEATRO, s/d 
brasileiro" ${ }^{11}$ e Décio, ao ser denunciado pelo Sbat ao presidente da República (Juscelino Kubitschek) por supostamente ter diminuído o Brasil "lá fora", a propósito de uma crítica dura a Joracy Camargo publicada na revista argentina Ficción, disse com todas as letras que "a arte não tinha nada que ver com patriotismo".

Ana Bernstein organiza e avalia a produção da crítica jornalística de seu autor dividindo-a em três períodos: os anos de formação, momento ainda não profissional, quando Décio estréia em Clima. Já trazia entretanto uma experiência rara entre nós, pois frequentava o teatro desde a infância e na juventude participou do teatro amador, como ator e fundador do Grupo Universitário de Teatro -GUT. Nos dois meses e meio que passou em Paris com Paulo Emílio em 1939, assistiu a várias companhias de vanguarda, incluindo-se a de Louis Jouvet, que acabou vivendo dois anos no Brasil por conta da guerra, e paradoxalmente nos foi extremamente útil do ponto de vista cultural; após o curso de filosofia na Universidade da Carolina do Norte, em 1941, Décio passou uma semana em Nova York, visitando o Actors Studio e assistindo a vários espetáculos. Portanto, à altura da estréia, o jovem Almeida Prado já tinha uma certa formação, ou, conforme suas palavras, "um parâmetro para julgar as coisas". Quanto à teoria do teatro ele a adquiriu pouco a pouco, a partir do livro Réflexions du comédien escrito por Jouvet, cujas concepções teóricas sintonizavam naquele momento com as transformações cênicas na França e no restante da Europa. Podem ser resumidas na importância de Copeau quanto à primazia do texto em relação aos outros elementos cênicos, e a defesa da convenção teatral em oposição ao naturalismo de Antoine e Stanislávski, cujo objetivo confessadamente era "expulsar o teatro do teatro".

Os leitores poderão ler em anexo, em A critica cúmplice, os 11 textos publicados por Décio em Clima, analisados por Ana no capítulo $2^{12}$, dentre os quais o primeiro e o último sublinham a importância do Teatro "Louis Jouvet" em São Paulo, na medida mesmo em que não se tratava de uma mera companhia estrangeira que se deslocava, com todos os vícios da improvisação - o que já era denunciado com muito mau humor por Martins Pena em seus Folhetins do século XIX. Tratava-se, sim, de um grupo articulado de bons atores, "chefiados por alguém, com um programa mais ou menos fixo" (p.256).

11 Cf. Schwarz, Roberto. "Sobre a 'Formação da Literatura Brasileira'”, Sequências Brasileiras, São Paulo, Companhia das Letras, 1999.

12 Cf. também Pontes, Heloisa, op. cit., p.105 ss. 
A partir desses primeiros textos, também é fácil observar o caráter empenhado do crítico iniciante, a compreensão da importância da crítica nas décadas de 1940 e 1950, quando todos batalhavam por um teatro moderno, sempre defasado dos centros hegemônicos, e a convicção de que História e crítica são indissociáveis. "Acho que a crítica é muito o jogo entre o particular e o universal" - afirma ele numa entrevista a Ana ( Apêndice-2)- " Se você fizer uma coisa puramente universal, você faz, de fato, uma ciência do teatro. Se você fizer uma coisa inteiramente particularizada, você não faz nem crônica; apenas você dá suas impressões".

Não deixa de ser curioso que alguns aspectos do palco denunciados por Décio naquelas páginas inaugurais até hoje persistam. Por exemplo, a existência (por ele condenada) do virtuose, cujo maior interesse seria a exibição de qualidades pessoais, "como se a interpretação fosse um fim em si mesma" (p.259); o compromisso entre teatro comercial e teatro de arte, cruzamento difícil de resolver equilibradamente em todas as artes, principalmente no teatro, ao mesmo tempo criação e comércio; o mero uso de fórmulas da moda, que tornam o espetáculo mecânico; percalços da encenação de textos clássicos por falta de formação de atores, pois seria necessário "um longo aprendizado, uma longa preparação da voz, de respiração, de dicção, de gestos, de movimentação, o conhecimento profundo de um estilo de representar" , o que não se faria sem escolas dramáticas). Outras questões são datadas, por exemplo o desenvolvimento do teatro nacional pelo amadurecimento de Os Comediantes enquanto grupo, precedido pela ação renovadora do amadorismo, e culminando na representação de Vestido de Noiva, em 1943 sob a direção de Ziembinski, citado acima. Em 0 Teatro Brasileiro Moderno Décio comenta o acontecimento, com uma animação a que não falta certa ironia risonha:

O choque estético, pelo qual se costuma medir o grau de modernidade de uma obra, foi imenso, elevando o teatro à dignidade dos outros gêneros literários, chamando sobre ele a atenção de poetas como Manuel Bandeira e Carlos Drummond de Andrade, romancistas como José Lins do Rego, ensaistas sociais como Gilberto Freyre, criticos como Álvaro Lins. Repentinamente, o Brasil descobriu essa arte julgada até então de segunda categoria, percebendo que ela podia ser tão rica e quase tão hermética quanto certa poesia ou certa pintura moderna. Evocou-se a propósito a grandeza da tragédia grega, discorreu-se sabiamente sobre os méritos do expressionismo alemão, que na véspera ainda ignorávamos, proclamou-se, com unanimidade raras vezes observada, a genialidade da obra de Nelson Rodrigues.(p.41) 
Nos anos de consolidação, segundo Bernstein, de 1946 (coincidindo com o início do teatro empresarial no Brasil) a 1964, o crítico define e amadurece os conceitos com que trabalha, mostra-se cuidadoso com a formação da platéia, o tom didático sobrepujando a livre reflexão estética, assim como na hierarquia texto/espetáculo, criação literária/crítica prevaleciam sempre as primeiras alternativas.

No último período, de 1964 a 1968, entendido pela ensaísta como o da transformação, dá-se a revisão crítica de alguns conceitos. 0 teatro amadurecera e crescera, o Arena e o Oficina, por exemplo, inauguraram novos estilos de representação, andavam com as próprias pernas, o fervor político era grande embora houvesse gorado o desejo de se fazer um teatro operário ${ }^{13}$. Afinal quem podia pagar as entradas era mesmo a classe média. Mesmo assim, apesar de algumas simplificações ideológicas dos grupos ${ }^{14}$, Décio sublinha 0 papel do Arena no cenário estético e político:

Por dez anos, de 1958 a 1968, funcionou [o Arena] como ponta de lança do teatro político brasileiro, encenando alguns espetáculos memoráveis, revelando atores e autores, e, antes de mais nada, realizando um notável trabalho de teorização quaisquer que sejam as restrições que a posteriori se lhe possam fazer. (0 Teatro Brasileiro Moderno, p.78)

Ana observa que, apesar de alguns pontos, existem características comuns aos três momentos da atuação de Décio. Um deles, a diferença entre ciência e crítica, pela interferência da subjetividade que dificulta ou impede juízos de validade objetiva. Por isso Décio nunca deixou de se considerar um crítico impressionista, mesmo porque, nos anos do Estado de S. Paulo, tinha de dar uma resposta imediata a partir do estímulo do espetáculo. Persistiu também a noção da encenação como um conjunto articulado entre todos os elementos do palco -o que o afastaria da "antipeça" ou do teatro da crueldade de sabor artaudiano- além da idéia de personalidade extraordinária, que definiria a natureza do grande ator (cf. cap. 4), elemento que se confunde com a

13 Peter Brook chamou ao teatro popular de "rough" (rústico) para evitar sua confusão com o "teatro burguês popularizado" (cf. cap. 1, The Empty Space, Penguin Books, 1968). A diferença, acho, evita muitos equívocos.

14 Décio avalia certos procedimentos estéticos da esquerda intelectual da época a partir de uma "consciência pesada pelo malogro de 1964, menos talvez pela derrota que pela ausência de luta" ( $O$ Teatro Brasileiro Moderno, São Paulo, Perspectiva,1988, p.76). Curiosamente essa conclusão é uma das vigas de sustentação de $O$ Motor da Luz (Rio, Ed. 34 Letras, 1994) livro notável de José Almino, que tem no golpe de 1964 um dos fulcros da fabulação. 
própria representação, pela efemeridade de sua natureza, sobrevivendo apenas na memória.

$\mathrm{Na}$ orelha que escreve para o livro, Mariangela Alves de Lima observa que Ana Bernstein não padece "a angústia relativista da produção teórica contemporânea" e serenamente afirma que Décio de Almeida Prado "foi o maior crítico teatral que o Brasil já teve", afirmação que eu diria unânime, ou quase. Mais que isso, "este livro foi escrito por uma pesquisadora que se deixa ensinar pelas coisas", o que significa que absorveu valores de seu autor: evitou a paralisia da reverência elogiosa e da exaltação superlativa, o que caracterizaria uma mera opinião, preferindo a pesquisa das fontes e a leitura criteriosa dos textos na formação do juízo. $\mathrm{Eu}$ acrescentaria ainda outro aspecto: no ítem "a crítica militante" (capítulo 3), Ana comenta a decisão do crítico quando decidiu publicar em livro seus textos jornalísticos. Haveria uma dupla razão: em primeiro lugar, o testemunho prestado a essa arte fugaz, num tempo em que o recurso do vídeo ainda não existia." Reunidos em livro [os textos] seriam comparáveis a instântaneos, que fixam rapidamente o presente do espetáculo, sem nada dizer do passado ou do futuro" (p.94). A segunda razão dizia respeito à criação de uma consciência teatral. Ou seja, naquele momento inicial, a crítica teria sobretudo "um caráter formativo e informativo, didático, menos preocupado com questões estéticas em si do que com a forma de tornar essas questões acessíveis e claras para o público leitor"(p.95).

Ora, sendo A Crítica Cúmplice o primeiro ensaio exclusivamente sobre a produção de Almeida Prado, Ana Bernstein certamente obedeceu ao mesmo caráter "formativo e informativo", indiscutivelmente útil a futuros pesquisadores. Rodeou por todos os lados o objeto de sua análise -o crítico e sua crítica- esmiuçando circunstâncias conjunturais, o diagnóstico cultural do Brasil e de nosso teatro, o empenho e a responsabilidade estética, social e política (nem sempre partidária) do Grupo Clima. Desafios intelectuais e constrangimentos de várias ordens não estão ausentes do retrato a bico de pena que é feito de Décio, de quem também é ouvido o depoimento e sua própria versão de muitos acontecimentos. Não preciso citar a suposta ojeriza do crítico em relação a Brecht, ou o seu "agradeço, mas não aceito a exclusão" no episódio da devolução dos prêmios ao Estado de S. Paulo em 1968, quando a classe teatral rompeu com todo e qualquer vínculo com aquele órgão da imprensa, excluindo-se entretanto os nomes de Décio e de Sábato Magaldi. Não custa lembrar também que diante das críticas ao TBC, inclusive por seu "italianismo" (de um certo momento em diante virou moda criticar o TBC, como, numa certa 
época, o CPC) a resposta de Décio foi clara: após concordar com a crítica (e listou todos os nomes estrangeiros) convidou os opositores "a raciocinarem em outro plano":

seríamos capazes de imaginar a fisionomia de São Paulo sem a contribuição dada pelos italianos, sucessivamente na agricultura, na indústria e nas artes? Desqualificariamos também brasileiros de primeira ou segunda geração, como Portinari, Volpi, Pancetti, Camargo Guarnieri? Em que categoria colocariamos Brecheret e Gianfrancesco Guarnieri, nascidos na Itália, de pais italianos? Onde, exatamente começa o Brasil? Há brasileiros mais brasileiros que outros? Ou todos que moram e trabalham aqui merecem esse título, certamente não racial? ${ }^{15}$

0 texto dispensa comentários.

Terminando essas notas, considero uma pena que o privilégio dado por Bernstein às críticas jornalísticas ${ }^{16}$, deixasse à produção acadêmica apenas o último capítulo ${ }^{17}$. É verdade que se trata de uma ampliação do que foi defendido como dissertação de mestrado, procurando a ensaísta articular os dois tipos de produção, direcionada sempre pelo caráter formativo. Mesmo assim eu gostaria de ter podido acompanhar de maneira mais detalhada, em A Critica Cúmplice, características da capacidade interpretativa de Almeida Prado, seja através da descrição mais minuciosa de algumas análises formais, seja quando ele rearruma a história de nossa literatura teatral, recolocando nesse painel algumas figuras capitais. Interpretando os textos sempre em relação somos muitas vezes surpreendidos por Décio. Por exemplo, quem suspeitaria que a febre de aforismos e paradoxos dos anos 20 do século passado tivesse algo a ver com o teatro de Oswaldo de Andrade, que só conhecemos como teatro ao final dos anos 60? Quem diria que a produção crítica de Alcântara Machado, "apocalíptico" e "profeta de uma nova era" poderia aproximá-lo, pelo tom doutrinário, e apesar de suas limitações, à pregação naturalista de Zola ou à campanha de Bernard Shaw a favor do ibsenismo?

No entanto, se esses textos de Alcântara Machado são nosso verdadeiro Prefácio de Cromwell, atacando violenta-

15 Em O Estado de s. Paulo, 10/out/1998.

16 Sobre a idéia de que o Suplemento não se pretendia "jornalístico", cf. Pontes, Heloisa, op. cit., p.209.

17 Flora Sussekind explica no prefácio do livro que o último capítulo foi ampliado para a publicação da tese, procurando conectar "os estudos históricos de Décio sobre a formação do teatro brasileiro à sua preocupação fundamental com a consolidação do teatro moderno e com o caráter, a seu ver, necessariamente formativo da crítica”(p.14). 
mente os pilares básicos da cultura oficial brasileira, eles não foram lidos e caíram no vazio. E quando de fato se iniciou a renovação teatral, entre 1940 e 1950, "esta se fez sem plano de conjunto, por avanços e recuos, por iniciativas às vezes antagônicas, quase todas de caráter individual" ${ }^{18}$.

Os exemplos desse quilate não são poucos. Mas compreendo que isso fugiria ao projeto de Ana Bernstein, com o pouco tempo de que dispôs para elaborar um trabalho de fôlego como este. Que ela continue, é o que todos desejamos.

18 Prado, Décio de Almeida. “O Teatro e o Modernismo”, Peças, Pessoas, Personagens, São Paulo, Companhia das Letras, 1993, p. 15 ss. 